\title{
Thinking about the burden of treatment
}

\author{
Should it be regarded as an indicator of the quality of care?
}

\author{
Frances S Mair professor of primary care research ${ }^{1}$, Carl R May professor of healthcare innovation ${ }^{2}$ \\ ${ }^{1}$ Institute of Health and Wellbeing, College of Medical, Veterinary and Life Sciences, University of Glasgow, Glasgow G12 9LX, UK; ${ }^{2} \mathrm{NIHR}$ CLAHRC, \\ Faculty of Health Sciences, University of Southampton, UK
}

Across the world healthcare systems are struggling to cope with increasing demands and costs. Rising life expectancy has been accompanied by an explosion in the prevalence of long term conditions and multimorbidity. ${ }^{1}$

Clinicians are working within legacy systems that were developed to deal with 19th century problems-they provide specialised responses to acute illness and infection. At the same time daily practice is strongly influenced by an ever expanding array of disease centred guidelines that don't map neatly to the realities of clinical practice, in particular the ubiquity of multimorbidity. ${ }^{2}$ The result is fragmented, poorly coordinated health services for those most in need-vulnerable patients with multimorbidity. ${ }^{3}$ Today's healthcare professionals are faced not only with rising disease-disease, drug-drug, and disease-drug interactions in multimorbid populations but with the increasingly evident consequences of socioeconomic disadvantage.

Meanwhile, patients, their families, and their extended social networks experience not only the burden of symptoms but the burden of treatment. ${ }^{4}$ This is an emerging but underinvestigated phenomenon. It has received increasing attention recently, and interest has been growing in how to define and better understand the concept.

Some of the key components of treatment burden have been teased out from systematic reviews ${ }^{56}$ and qualitative studies in people with a range of chronic illnesses and their caregivers. ${ }^{7-9}$ The findings show that patients and caregivers are often put under enormous demands by healthcare systems. Such demands can include substantially changing their behaviour and policing the behaviour of others in order to adhere to recommended lifestyle modifications. Patients or their caregivers often have to monitor and manage their symptoms at home, which can include collecting and inputting clinical data. Adhering to complex treatment regimens and coordinating multiple drugs can also contribute to the burden of treatment. ${ }^{10}$ To secure eligibility for services patients are often faced with complex administrative systems, and accessing, navigating, and coping with uncoordinated health and social care systems can further add to the burden.
The burden continues to increase as healthcare systems shift an ever growing list of management responsibilities and tasks on to patients and their caregivers. This is real work, which requires considerable effort from patients, their caregivers, and their extended social networks. For many it can be overwhelming - it is time consuming and calls for high levels of numeracy, literacy, and, sometimes, technical knowledge. Manual dexterity and practical skills are often required. People who are socially isolated, poorly educated, have low health literacy, are cognitively impaired, do not speak the local language, or who have sensory or physical challenges are unlikely to prosper in such contexts. Nor are people without these problems who are time poor. People who work three jobs to pay the rent may find it hard to adhere to the requirements of multiple clinical guidelines. Such people will struggle to adhere to treatment recommendations, thereby risking poor outcomes and the waste of increasingly scarce healthcare resources.

A first step towards lessening the burden of treatment is the development of methods to measure the burden. Such instruments should include more than just treatment side effects. They need to encompass the disruptive effects that adherence to treatment has on working lives (for example, having to repeatedly go to clinics for tests) and on social lives (for example, having to curtail activities because of treatment side effects). Hidden costs are also a problem - the expense of getting to clinic appointments, taking time off work, and paying for all or some of the treatment should be taken into account. In addition, the effort required to learn self management skills, such as how to give yourself or dependent others regular injections, ought to be included. Finally, coping with problems caused by discontinuity and fragmented care, as well as the potential psychosocial burden of being medicalised and turned into a patient must be considered. Preliminary work has been undertaken to develop scales and measures of burden, but further work is needed to address individuals' capacity to cope with a given burden. ${ }^{11} 12$

The burden of treatment imposed by the delivery of healthcare services could become a key barometer of quality. However, both instruments and interventions will need to be designed to take account of differences between healthcare systems and 
combinations of conditions as well as gradients of individual capacity to cope with the burden. ${ }^{13}$ So, although evidence indicates that burden of treatment has many generic features, it is also likely to differ between Nebraska and Norfolk and between astrocytoma and asthma.

Not all treatment burden is unreasonable or avoidable. For example, polypharmacy may be necessary to control the symptoms of multiple conditions or to reduce the risk of disease exacerbations or long term adverse events. Some treatment burden may be situational and transient, relating to a specific acute crisis. Moreover, the burden may be better tolerated by people who are well equipped and resilient than by those who are not. Methods for accurately predicting those at greatest risk of being overwhelmed by treatment burden are not yet available, but a reasonable starting point may be to assume that everyone is at risk.

We have previously argued for "minimally disruptive medicine" - an approach to patient care that emphasises individual preferences, takes account of multimorbidity, and seeks to reduce the workload for patient and caregiver. ${ }^{14}$ Interventions that implement minimally disruptive medicine and attack the burden of treatment need to provide coordinated care that is person rather than disease centred and is maximally supportive. While we wait for reliable, validated measures of treatment burden, a simple question from the doctor may suffice: "Can you really do what I am asking you to do?"

Competing interests: We have read and understood BMJ policy on declaration of interests and declare the following interests: both authors supervise a PhD studentship funded by the Chief Scientist's Office, Scotland, that addresses the subject of treatment burden in stroke and both co-lead the International Workgroup for Minimally Disruptive Medicine with Victor Montori.
Provenance and peer review: Commissioned; not externally peer reviewed

1 Barnett K, Mercer SW, Norbury M, Watt G, Wyke S, Guthrie B. Epidemiology of multimorbidity and implications for health care, research, and medical education: a cross-sectional study. Lancet 2012;380:37-43.

2 Guthrie B, Payne K, Alderson P, McMurdo ME, Mercer SW. Adapting clinical guidelines to take account of multimorbidity. BMJ 2012;345:e6341.

3 Payne RA, Abel GA, Guthrie B, Mercer SW. The effect of physical multimorbidity, mental health conditions and socioeconomic deprivation on unplanned admissions to hospital: a retrospective cohort study. CMAJ 2013;185:E221-8.

4 May CR, Eton DT, Boehmer K, Gallacher K, Hunt KJ, MacDonald S, et al. Rethinking the patient: using burden of treatment theory to understand the changing dynamics of illness. BMC Health Serv Res 2014;14:281.

5 Sav A, King MA, Whitty JA, Kendall E, McMillan SS, Kelly F, et al. Burden of treatment for chronic illness: a concept analysis and review of the literature. Health Expect 2013;15:351-9.

6 Gallacher K, Morrison D, Jani B, Macdonald S, May CR, Montori VM, et al. Uncovering treatment burden as a key concept for stroke care: a systematic review of qualitative research. PLOS Med 2013;10:e1001473.

7 Bohlen K, Scoville E, Shippee ND, May CR, Montori VM. Overwhelmed patients: a videographic analysis of how patients with type 2 diabetes and clinicians articulate and address treatment burden during clinical encounters. Diabetes Care 2012;35:47-9.

8 Sav A, Kendall E, McMillan SS, Kelly F, Whitty JA, King MA, et al. "You say treatment, I say hard work": treatment burden among people with chronic illness and their carers in Australia. Health Soc Care Community 2013;21:665-74.

9 Gallacher K, May C, Montori VM, Mair FS. Understanding patients' experiences of treatment burden in chronic heart failure using normalization process theory. Ann Fam Med 2011;9:235-43.

10 Gallacher K, Batty GD, McLean G, Mercer SW, Guthrie B, May CR, et al. Stroke, multimorbidity and polypharmacy in a nationally representative sample of 1424378 patients in Scotland: implications for treatment burden. BMC Med 2014;12:151.

11 Eton DT, Ramalho de Oliveira D, Egginton JS, Ridgeway JL, Odell L, May CR, et al. Building a measurement framework of burden of treatment in complex patients with chronic conditions: a qualitative study. Patient Relat Outcome Meas 2012;3:39-49.

12 Tran VT, Montori VM, Eton DT, Baruch D, Falissard B, Ravaud P. Development and description of measurement properties of an instrument to assess treatment burden among patients with multiple chronic conditions. BMC Med 2012;10:68.

13 Shippee ND, Shah ND, May CR, Mair FS, Montori VM. Cumulative complexity: a functional, patient-centered model of patient complexity can improve research and practice. J Clin Epidemiol 2012;65:1041-51.

14 May C, Montori VM, Mair FS. We need minimally disruptive medicine. BMJ 2009;339:b2803

Cite this as: BMJ 2014;349:96680

(๑) BMJ Publishing Group Ltd 2014 